\title{
"5X FAVELA, AGORA POR NÓS MESMOS": UM ESTUDO SOBRE LEGENDAGEM E AUDIODESCRIÇÃO
}

\author{
Érica Lima \\ Marcella Wiffler Stefanini \\ Universidade Estadual de Campinas \\ Campinas, São Paulo, Brasil
}

Resumo: Este artigo apresenta um estudo sobre duas modalidades de tradução audiovisual (TAV), a legenda para ouvintes e a audiodescrição (AD), presentes no filme $5 x$ favela, agora por nós mesmos, com o objetivo de demonstrar não só sua importância como recurso de acessibilidade, mas também como elemento de significação do filme. Com base na fundamentação teórica de Araújo (2008), Franco e Araújo (2011), Chaume (2004), Diaz-Cintas (2007), Romero-Fresco (2013), entre outros pesquisadores da área, traçou-se uma comparação entre a legenda em português para ouvintes, presente no DVD do filme, e o que seria a legenda para surdos e ensurdecidos (LSE), recurso não oferecido. Os resultados da análise confirmam a importância dos recursos da TAV para a construção de sentidos e destacam as características predominantes da $\mathrm{AD}$ e as dificuldades decorrentes da falta da LSE.

Palavras-chave: Acessibilidade; Audiodescrição; Legenda para ouvintes; Legenda para surdos e ensurdecidos; Tradução audiovisual

\section{"5X FAVELA, AGORA POR NÓS MESMOS": A STUDY ABOUT SUBTITLING AND AUDIO DESCRIPTION}

\begin{abstract}
The aim of this article is to provide an overview of two modalities of Audiovisual Translation (AVT), the subtitling for hearing viewers and Audio Description (AD), followed by a study of the film " $5 \mathrm{x}$ favela, now by ourselves", demonstrating not only the importance of AVT as an accessibility resource, but also as an element of significance of the
\end{abstract}


film. Based on Araújo (2008), Franco and Araújo (2011), Chaume (2004), Diaz-Cintas (2007), Romero-Fresco (2013), among other researchers, a comparison was made between the Portuguese subtitles featured on the DVD of the movie, and what would be the Subtitling for the Deaf and Hard-of-hearing (SDH), an important feature the DVD does not offer. The results obtained in the analysis show the relevance of the TAV for the construction of meanings, the predominant characteristics of the AD and the difficulties arising from the absence of the SDH.

Keywords: Accessibility; Audio Description; Audiovisual Translation; Subtitling for Hearing Viewers; Subtitling for the Deaf and Hard-ofhearing

\section{Contextualização}

O surgimento do cinema, no final do século XIX, possibilitou que outras mídias audiovisuais fossem desenvolvidas no século $\mathrm{XX}$. Com o advento da internet e das tecnologias móveis, a produção e o compartilhamento de produtos audiovisuais intensificaram-se e eles passaram a fazer cada vez mais parte do nosso dia a dia. Contudo, o acesso a essas novas tecnologias ainda é limitado, seja em função do seu alto valor monetário, que não condiz com o poder aquisitivo de grande parte da população, seja em função da sua própria natureza audiovisual, excluindo, total ou parcialmente, a parcela da população com deficiência visual ou auditiva, que fica, de certa forma, privada dessa cultura audiovisual. A fim de incluir esse grupo no novo contexto sócio-histórico-cultural, na área da tradução audiovisual (doravante TAV) foram desenvolvidos, por exemplo, os recursos de audiodescrição (AD), janela de língua de sinais (LIBRAS), legenda interlingual, legenda intralingual e legenda para surdos e ensurdecidos (LSE). Entretanto, apesar da existência de tais recursos e do amparo da lei brasileira ${ }^{1}$, na práti-

\footnotetext{
${ }^{1}$ A lei federal 10.098 de dezembro de 2000 reconhece a AD como um direito adquirido da comunidade cega e a lei federal 10.463 de abril de 2002, por sua vez, reconhece a LIBRAS como língua oficial da comunidade surda, além da existência da lei de acessibilidade, decreto lei 5.296 de dezembro de 2004, que regulamenta o funcionamento dessas modalidades de TAV.
}

Cad. Trad., Florianópolis, v. 38, no 2, p. 219-240, mai-ago, 2018 
ca, não se verifica a ampla presença desses recursos de acessibilidade no Brasil. Com relação à $\mathrm{AD}$, em um pequeno levantamento sobre a presença do recurso em museus de arte brasileiros, constatou-se que a maioria não oferece $\mathrm{AD}$ das obras. Com relação à acessibilidade da comunidade surda, é possível observar a existência da legenda em português, contudo, nem todas são do tipo LSE, que contém, entre outras características, sons que porventura apareçam no vídeo e referência à pessoa que está falando. Mesmo a legenda oferecida por algumas emissoras de televisão brasileira, e disponível através da tecla SAP, chamada closed caption, apesar de ser um recurso válido, não é considerado muito eficaz, como já demonstraram diferentes estudos realizados pelo Instituto Cearense de Educação dos Surdos (ICES) em Fortaleza (cf. ARAÚJO, 2004; 2005; 2007; 2008).

Em razão disso, estudos sobre as modalidades de TAV se fazem necessários a fim não só de aperfeiçoar as técnicas envolvendo a produção de cada uma delas - que devem sempre levar em consideração o público alvo, no caso, o cego ou com pouca visão, para a $\mathrm{AD}$, e surdo ou ensurdecido, para a LSE -, como também de divulgar a situação de difícil acesso dessa parcela da população brasileira às mídias audiovisuais, além de demonstrar a necessidade de investimento em tais recursos e preocupação social para que a inclusão de fato aconteça.

Com base nessas considerações iniciais, este artigo pretende apresentar uma análise da legenda para ouvintes e da AD do filme "5x favela, agora por nós mesmos". Para tanto, apresentamos, na primeira parte, uma contextualização da TAV, em seguida, destacamos alguns aspectos da análise do filme, e, por último, algumas considerações finais e possibilidades de estudos futuros.

\section{Tradução audiovisual}

De acordo com Franco e Araújo (2011), no início, a designação "tradução audiovisual” não foi consensual. Yves Gambier, em tex- 
to publicado em 2003, explica que os primeiros trabalhos na área usavam o termo film translation, ou tradução de filmes, considerando apenas a produção voltada para o cinema, razão pela qual ele havia proposto o uso do termo screen translation, referindo-se a outras mídias, como a televisão ou o computador. Contudo, Franco e Araújo, embasadas nos estudos de Díaz-Cintas (2005), esclarecem que "audiovisual inclui todos os espaços onde há um sinal acústico e um sinal visual, independentemente de ser transmitido através de uma tela (que pode ser ao vivo ou não) ou de um palco (sempre ao vivo)" (FRANCO E ARAÚJO 2011, p. 3), e, por isso, preferem o uso do termo tradução audiovisual, uma vez que o termo screen refere-se apenas às transmissões via tela.

As autoras classificam as modalidades de TAV em: legendagem para ouvintes; LSE; legendagem eletrônica ou surtitling; dublagem; voice-over e AD. Explicam, ainda, que a LSE e a AD, por não se caracterizarem como formas de tradução entre línguas (ou tradução propriamente dita), não foram inicialmente consideradas modalidades de TAV pela comunidade acadêmica e científica. Apesar disso, muitos estudiosos, dentre os quais elas se incluem, defendem, com base na conhecida classificação de Jakobson (2010 [1963]), que a LSE seria uma tradução intralingual e a AD uma tradução intersemiótica, isto é, modalidades de TAV.

Trazendo maior especificidade para a área, Chaume (2004) define texto audiovisual como "uma construção semiótica que compreende uma série de códigos significativos que operam simultaneamente na produção do significado" (CHAUME 2004, p.16) ${ }^{2}$. Dentre esses códigos significativos, o autor elenca o código linguístico e paralinguístico, o código referente à trilha sonora, ao arranjo de som, aos efeitos especiais, à iconografia, à fotografia, ao planejamento (importante nos casos de dublagem, quando há close-up e a tradução precisa respeitar o movimento dos lábios, recurso conhecido como phonetic ou lip synchrony) e à mobilidade

2 "an audiovisual text is a semiotic construct comprising several signifying codes that operate simultaneously in the production of meaning”. (Todas as traduções cujas citações também são apresentadas em outra língua são nossas).

Cad. Trad., Florianópolis, v. 38, n 2, p. 219-240, mai-ago, 2018 
(importante nos casos de legendagem, quando o movimento do personagem tem de estar de acordo com a frase legendada), ao código gráfico e sintático. Segundo ele, todos esses elementos são articulados para construir uma estrutura semântica a ser, posteriormente, desconstruída pelo leitor/espectador, que interpretará o conjunto do texto audiovisual. É por isso que, para o autor, compete ao tradutor não só traduzir o texto linguístico, mas atentar aos outros elementos que constituem o texto audiovisual e de que forma eles se relacionam com os elementos linguísticos (CHAUME, 1997). Por isso, sugere que haja um estudo conjunto entre a TAV e os estudos fílmicos, um aspecto retomado por Romero-Fresco (2013), que também acredita na necessidade de os tradutores estudarem o cinema e de os cineastas estudarem as modalidades de TAV. Segundo ele, falta diálogo entre o processo tradutório e o processo de criação e produção de qualquer texto audiovisual, o que resulta em traduções baseadas somente na interpretação do tradutor, já que esse não tem acesso ao diretor, roteiristas ou atores, e tampouco está presente no momento da produção. Para resolver isso, Romero-Fresco (2013) sugere que a tradução passe a fazer parte da produção do filme e defende que seja feita em conjunto com a equipe criativa, cunhando o termo accessible filmmaking, que traduzimos por acessibilidade cinematográfica.

Romero-Fresco (2017) lembra que, no início do século XX que marca o surgimento do cinema -, os primeiros filmes eram mudos, portanto, precisavam de legenda para situar o público e representar o diálogo entre os personagens, de modo que a legenda era pensada durante o processo de produção do filme, como parte da sua criação, e inserida no filme posteriormente. Depois, surgiram os filmes parcialmente mudos e, com a presença do áudio, apresentaram-se duas opções de tradução: a legendagem e a dublagem, ambas feitas após a produção do filme. Alguns produtores optavam pela chamada multiple-language version, ou seja, produziam o filme várias vezes e em línguas diferentes, de modo que os atores e, ocasionalmente, os diretores, mudavam em cada uma das versões. Contudo, essa opção era muito cara e logo a legen- 
dagem e a dublagem se consolidaram como métodos de tradução desvinculados do processo criativo. Como sintetiza o autor, a TAV "nasceu como um elemento de pós-produção nos filmes mudos, ocupou uma posição central no processo de produção das versões em múltiplas linguagens (que eram efetivamente "localizadas") e desde então foi consignada ao processo de distribuição" (ROMERO-FRESCO, 2017, s/p) $)^{3}$.

Entre as modalidades de TAV, trataremos primeiramente da LSE e, logo em seguida, da AD, que fazem parte das análises apresentadas. A LSE, considerada por Díaz-Cintas (2007) como uma prática sociolinguística da modalidade oral para a modalidade escrita da língua, consiste em informar 1) o que se diz; 2) quem diz; 3) como diz; 4) o que se ouve e 5) o que se vê (quando grafado em outro idioma). Araújo (2008), por sua vez, enfoca a identificação dos falantes e a inclusão de efeitos sonoros. No Brasil, costuma-se indicar o nome do falante entre colchetes e isso deve ser feito em toda troca de turno, em especial diante da presença de dois ou mais falantes na mesma cena. Recomenda-se que seja feita pelo nome ou pelo sexo (quando o nome for desconhecido). Além de identificar quem emite o discurso, a LSE também precisa indicar como se emite esse discurso, explicitando suas características paralinguísticas, ou seja, se o falante grita, gagueja, sussurra, etc. Díaz-Cintas recomenda que essa indicação seja feita entre parênteses.

A inclusão de efeitos sonoros é igualmente importante. DíazCintas sugere que as músicas que tenham um peso maior no argumento da ação ou na caracterização dos personagens sejam legendadas como se fossem diálogos, precedidas de uma nota musical, para indicar que se trata de uma música. As demais não precisam ser legendadas, mas recomenda-se que sejam referenciadas de modo objetivo, indicando o tipo de música. Além disso, a LSE

\footnotetext{
3 "it was born as a post-production element of silent films, it occupied a central position in the production process of multiple-languages versions (which were effectively localised) and since then has been consigned to the distribution process".
} 
deve ficar na tela para que espectador tenha tempo não apenas de ler a legenda, mas também de acompanhar as imagens.

Segundo Araújo, "a condensação e a edição das legendas são elementos fundamentais para tornar mais eficazes a leitura e compreensão destas para os espectadores surdos" (2008, p. 63), pois a língua oficial do surdo é a língua de sinais e, por isso, muitos não leem com a mesma velocidade dos ouvintes, razão pela qual a velocidade da LSE deve ser menor que a velocidade da legenda para ouvintes. Ainda segundo a autora, "as legendas para surdos devem condensar aproximadamente $30 \%$ daquilo que é falado, ou seja, para cada 1s de fala, devemos traduzir o que foi dito com 14 caracteres" (2008, p. 74). O Guia para produções audiovisuais acessíveis (ARAÚJO et all, 2016 - doravante Guia), por sua vez, recomenda que a LSE seja elaborada a partir dos parâmetros técnicos da legenda para ouvintes, de modo que a velocidade seja a mesma e varie entre 145,160 ou 180 palavras por minuto, o que corresponde a 25, 28 ou 30 caracteres por linha (2016, p. 43-44). Entre os demais critérios de elaboração da LSE estão: legendas amarelas em fundo transparente; identificação do falante entre colchetes sempre que houver mudança de turno; voz em off vinda da televisão, do telefone, do rádio, de alguém que não aparece na tela em itálico; efeitos sonoros sempre traduzidos; uso da norma culta do português; nota musical sinalizando a música, etc. (Araújo, 2008, p. 75).

Em relação à $\mathrm{AD}$, recorremos à definição de Franco e Araújo, que a classificam como: "a tradução em palavras das impressões visuais de um objeto, seja ele um filme, uma obra de arte, uma peça de teatro, um espetáculo de dança ou um evento esportivo" (2011, p.17), e tem como objetivo tornar esses produtos acessíveis a pessoas com deficiência visual, beneficiando também pessoas que, por qualquer motivo, não têm acesso à imagem do produto audiovisual. Segundo as autoras, a AD pode ser pré-gravada, como em filmes, programas de TV e obras de arte, ou pode ser ao vivo, como normalmente acontece em eventos, peças de teatro e apresentações de dança. Díaz-Cintas (2010) identifica um terceiro 
tipo de AD: a gravada para audioguias, muito comuns em museus e exposições de arte.

Benecke descreve a $\mathrm{AD}$ como "a técnica usada para fazer o teatro, o cinema e os programas de TV acessíveis ao público cego e com deficiência visual: uma narrativa adicional descreve a ação, linguagem corporal, expressões faciais, cenário e figurino" (2004, p. 1$)^{4}$. O autor explica que o roteiro da AD costuma ser elaborado por um grupo de três pessoas, uma delas cega. A necessidade de duas pessoas videntes para a confecção do roteiro parte do pressuposto de que duas pessoas que assistem a mesma cena não veem as mesmas coisas, tampouco a interpretam da mesma forma. Por isso, para que a $\mathrm{AD}$ seja a mais objetiva e imparcial possível, o roteiro é elaborado por três pessoas.

Para Casado (2007), a AD precisa concentrar-se na descrição de elementos visuais, diferenciados em não-verbais e verbais. Dentre os primeiros, ela destaca o personagem (sua roupa, atributos físicos, expressões faciais, linguagem corporal, etnia e idade); a ambientação (elementos espaciais e temporais); e por último, as ações que se sucedem. Além desses, a autora ressalta a importância da descrição de elementos visuais verbais como didascálias (comuns no cinema mudo para a indicação de ações, espaços, falas, etc.); títulos, créditos, frases (como "continuará"); legendas (contendo letras de música, por exemplo), dentre outros escritos. De preferência, a AD deve ser inserida entre os diálogos e poucas são as exceções em que se admite a sobreposição da AD a outros elementos acústicos. Em hipótese alguma, a AD deve ser inserida sobre o diálogo principal, sobre os efeitos sonoros (quando esses são importantes para a história ou complementam a descrição), ou sobre música de fundo importante.

A partir dessa pequena contextualização e caracterização dos dois recursos de TAV, passamos, a seguir, para a análise das legendas e da $\mathrm{AD}$ do filme.

\footnotetext{
4 "the technique used for making theatre, movies and TV programmes accessible to blind and visually impaired people: an additional narration describes the action, body language, facial expressions, scenery and costumes."
} 


\section{5x favela, agora por nós mesmos}

O documentário "5x favela, agora por nós mesmos" (2010), produzido por Renata de Almeida Magalhães e Carlos Diegues, traz cinco curtas-metragens de cerca de 20 minutos cada, cujo enredo se desenvolve nas comunidades do Rio de Janeiro, no mesmo estilo do filme homônimo $5 x$ favela (1962). A versão de 2010 é dirigida por jovens moradores das comunidades cariocas que participaram de oficinas de capacitação em audiovisual ministradas por grandes nomes do cinema, como Walter Salles, Ruy Guerra e Fernando Meirelles. Foi o grande vencedor do festival de Paulínia de 2010, com sete prêmios, incluindo o de melhor filme e melhor roteiro, e foi exibido em caráter hors compétition no Festival de Cannes. O filme de 1962, por sua vez, foi realizado por jovens cineastas de classe média que foram até as favelas registrar e denunciar a realidade da comunidade carioca, porém, a partir da perspectiva da classe média, ou seja, de quem não vive essa realidade.

Em relação às legendas oferecidas pelo DVD, é necessário reforçar que foram elaboradas para o público ouvinte e, portanto, seguem padrões diferentes dos esperados em LSE. Contudo, considerando tratar-se do único recurso de acessibilidade disponível para o público com deficiência auditiva, torna-se relevante fazer uma análise comparada entre o que se espera de uma LSE e o que é oferecido pelo DVD do filme, enfocando especialmente as possíveis dificuldades de interpretação decorrentes da falta da LSE.

Um dos principais problemas que a legenda em português traz ao público surdo é a velocidade. Por se tratar de uma quase transcrição da fala dos personagens, ela contém muita informação. Além disso, seu tempo de exposição na tela precisa estar em sincronia com o tempo em que os personagens estão falando, ou seja, movendo os lábios. Muitas vezes, isso resulta em tempo insuficiente para a leitura, como pode ser observado em dois exemplos do filme: o primeiro é um diálogo que se dá entre os personagens Maycon e Eduardo. Para esse diálogo, foram feitas duas inserções de legenda: a primeira, na figura 1, contém 44 caracteres e tempo 
de exposição de $1 \frac{1}{2} 2 \mathrm{~S}$ (velocidade de 29,3 caracteres/s), e a segunda, vista na figura 2 , contém 45 caracteres e tempo de exposição de $2 \mathrm{~s}$ (velocidade de 22,5 caracteres/s).

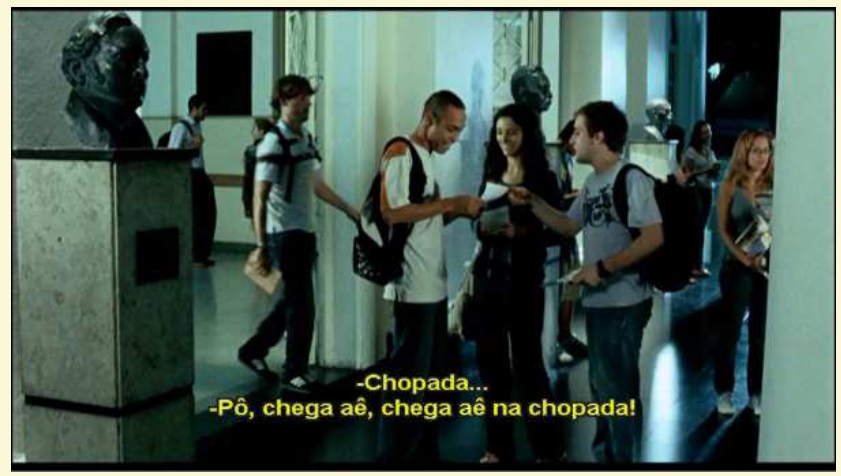

Figura 1

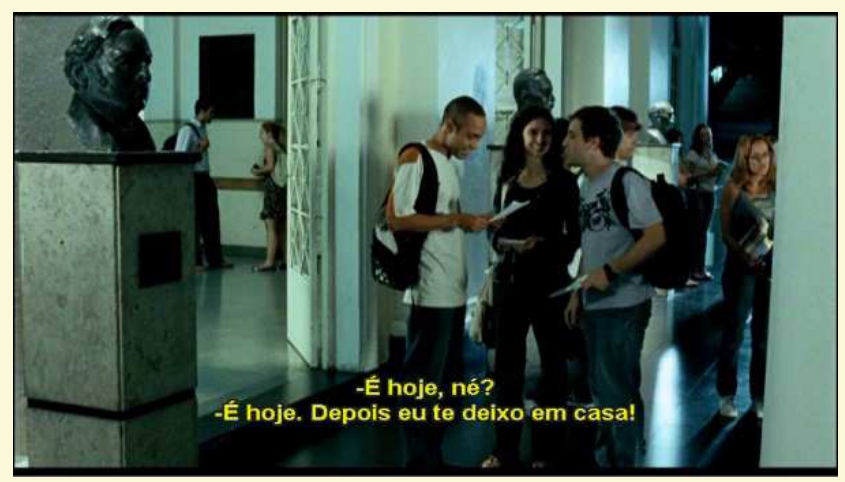

Figura 2

O segundo exemplo é um diálogo entre o tratador de cavalos e o guarda, retirado do segundo curta-metragem. Para esse diálogo, foram feitas duas inserções de legenda: a primeira (figura 3) contém 58 caracteres e tempo de exposição de $1 \frac{1}{2} \mathrm{~s}$ (velocidade de 38,6 caracteres/s), e a segunda, (figura 4), contém 45 caracteres e tempo de exposição de $2 \frac{1}{2} 2 \mathrm{~s}$ (velocidade de 18 caracteres/s). Além 
do problema da velocidade, nesse exemplo, a legenda deveria estar em itálico, uma vez que o falante, o guarda, não está em cena, e há o enquadramento do tratador.

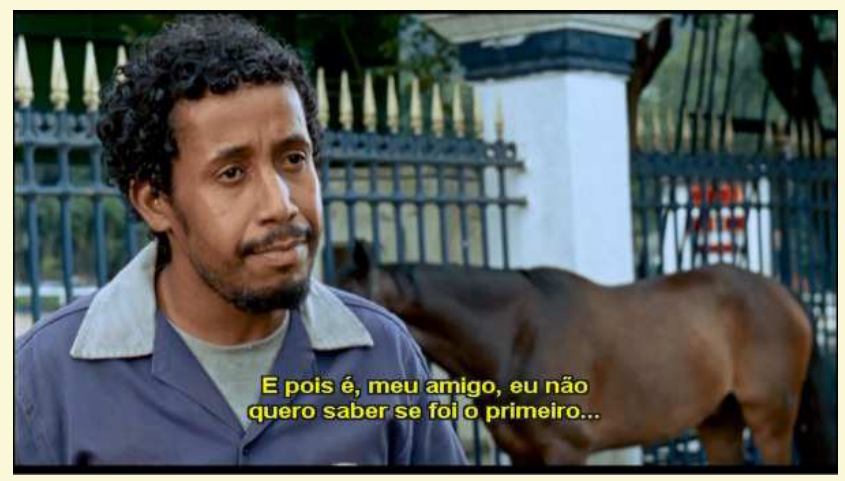

Figura 3

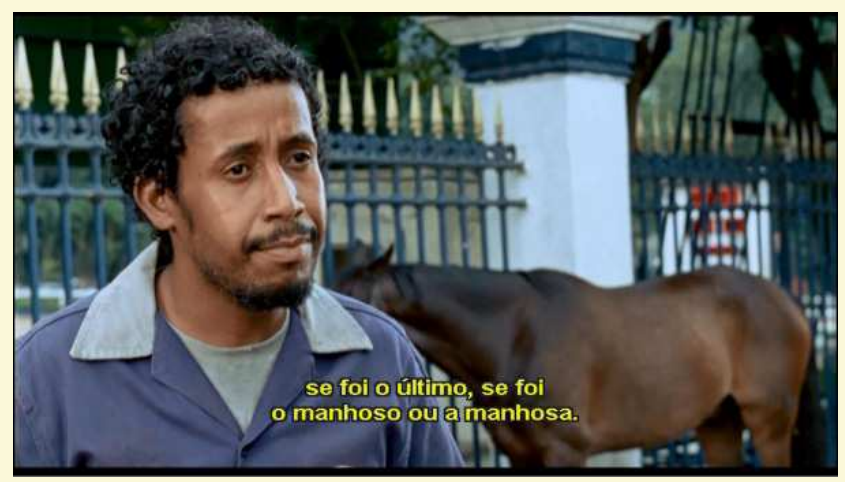

Figura 4

Esses dois momentos mostram que as legendas ficam na tela por tempo insuficiente, sendo impossível finalizar a leitura antes do aparecimento da segunda inserção, o que pode resultar em dificuldade de compreensão. Araújo (2008) recomenda uma velocidade de 14 caracteres por segundo para a LSE, valor ultrapassado nas legendas acima. Idealmente deveria haver, segundo recomendação do Guia (2016), a redução da informação textual. 
Outra dificuldade que a legenda para ouvintes apresenta ao público surdo e ensurdecido é a ausência de identificação dos falantes e dos efeitos sonoros. Quando não se sabe quem está falando, a tendência é tentar descobrir, de modo que o espectador pode desviar o olhar da parte inferior da tela, onde geralmente fica a legenda, para tentar deduzir pelas imagens. Para ilustrar essa dificuldade, selecionou-se um exemplo em que dois diálogos ocorrem simultaneamente e intercalados: Flávio e seus amigos estão saindo da escola quando Alex se aproxima e chama Flávio, que se afasta do grupo para conversar com Alex. Nesse momento, o diálogo entre eles ocorre simultaneamente ao diálogo dos amigos de Flávio:

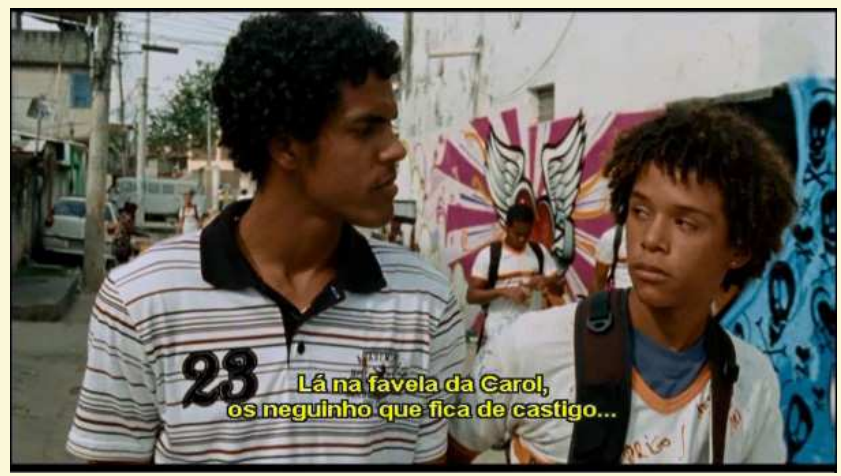

Figura 5

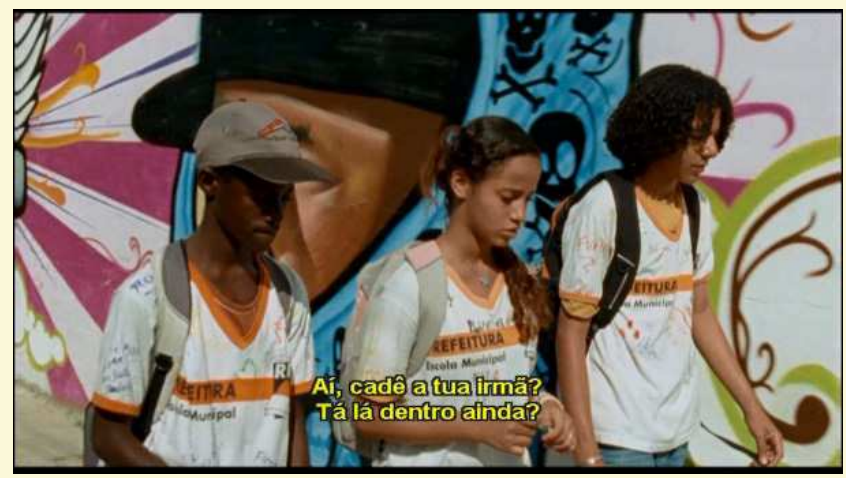

Figura 6

Cad. Trad., Florianópolis, v. 38, $\mathrm{n}^{0}$ 2, p. 219-240, mai-ago, 2018 


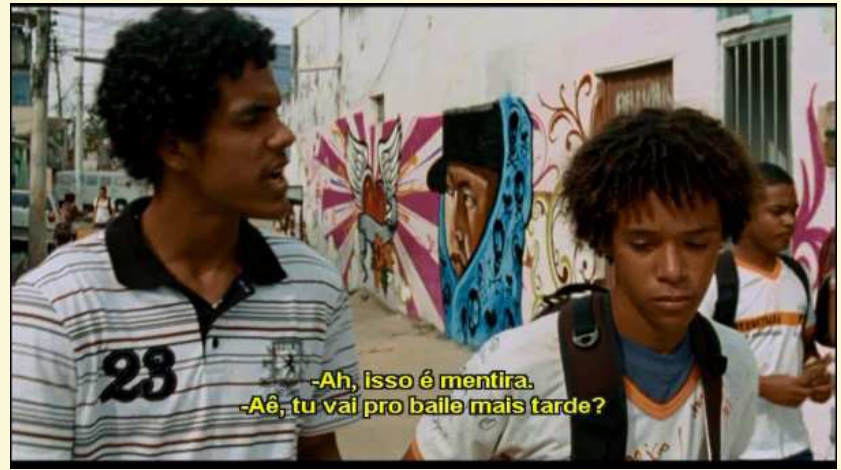

Figura 7

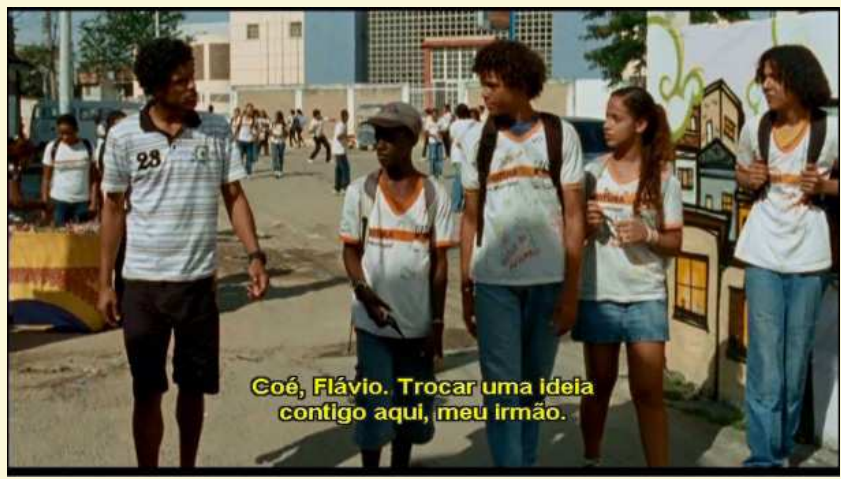

Figura 8

A respeito da identificação dos falantes, o Guia orienta para que seja feita toda vez que houver troca de turno, em especial diante da presença de dois ou mais falantes na mesma cena, além de sugerir que a cada novo enquadramento seja feita nova legenda. O problema da legenda acima é que ela não respeita a mudança de enquadramento, já que a legenda correspondente ao diálogo dos amigos é antecipada e surge na tela quando a câmera ainda enquadra Flávio e Alex. 
Com relação à identificação dos efeitos sonoros, além de algumas cenas em que há tiros no terceiro curta-metragem, há também cenas em que a música se sobrepõe ao diálogo e, portanto, não há legenda. Essa ausência por um longo período pode resultar em ansiedade do espectador com deficiência auditiva, por isso, sugere-se que na cena em que Maycon e Sofia dançam, no primeiro curta-metragem, haja referência à música que toca na balada, por exemplo, [música funk].

Outra cena na qual seria importante fazer referência à música aparece no quarto curta-metragem, quando Flávio e seus amigos estão voltando para casa e interagem com os moradores da comunidade. Nessa sequência, eles conversam, mas não há acesso ao que falam, pois a música toma conta da cena. Por isso seria importante inserir uma legenda identificando a música, para que o público surdo não se preocupe com o fato de os personagens mexerem a boca e não haver legenda.

No terceiro curta-metragem, seria interessante fazer referência ao som do violino na cena da morte de Jota e Marcinha, uma vez que o título da história é Concerto para violino e o instrumento aparece no chão ao lado dos corpos mortos, adquirindo um significado para o enredo que não pode ser ignorado. Nesse curta, há também um tiroteio que, para o público com deficiência auditiva, deveria ser identificado, porque logo após o som de tiros Jota chega machucado na casa de Marcinha.

Outra característica que pode representar uma dificuldade para o público com deficiência auditiva são as marcas de oralidade, tais como repetição, uso de expressões coloquiais, construções sintáticas pouco comuns na linguagem escrita etc., como nos exemplos seguintes: 


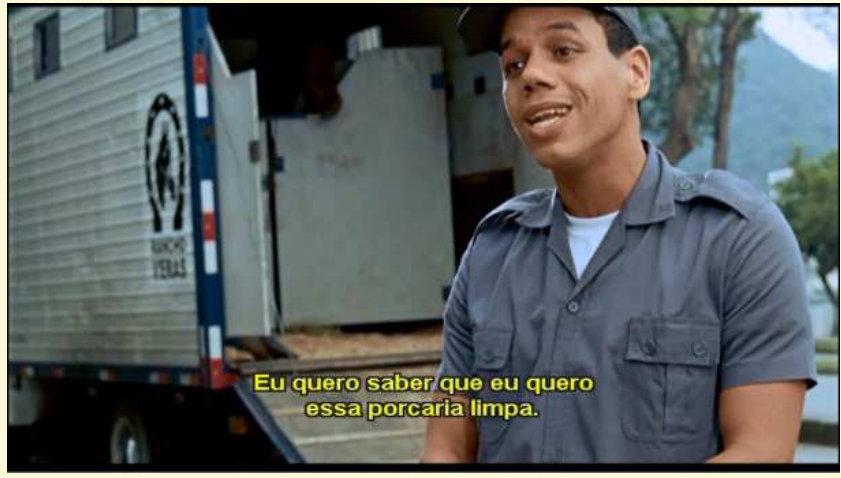

Figura 9 (31min20s)

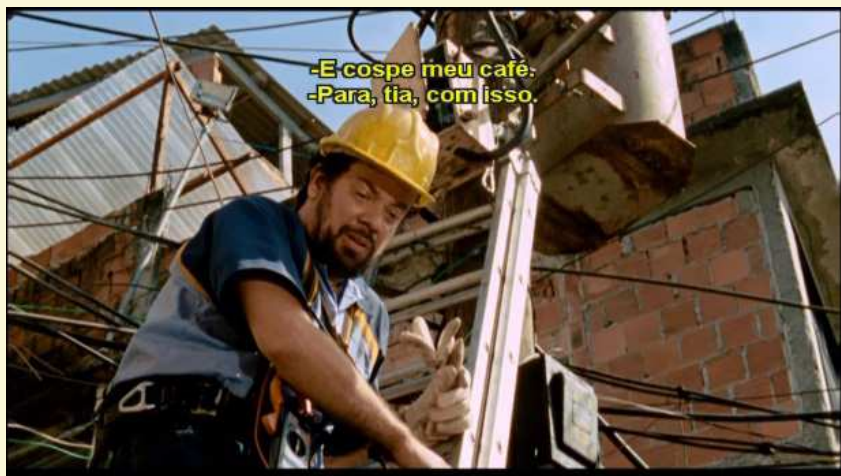

Figura $10(1 \mathrm{~h} 24 \mathrm{~min} 52 \mathrm{~s})$

Segundo o Guia, "há marcas muito fortes de regiões, culturas, idades etc. que fazem parte da caracterização" (2016, p. 66) e não devem ser suprimidas. Por outro lado, as hesitações, a fala "telegráfica" e a segmentação podem ser apagadas ou agrupadas em grupos maiores. Por fim, algo que se repete e que pode causar problema na interpretação é a falta de acentuação, como no caso de é por $e$. 


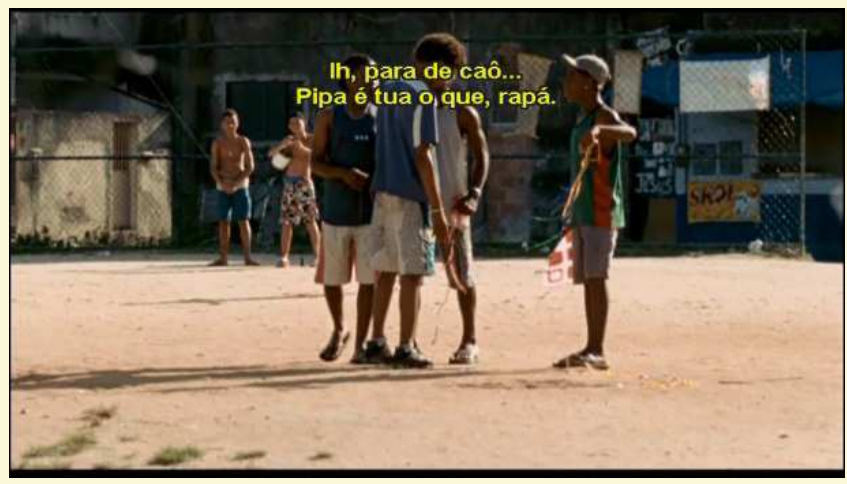

Figura 11 (1h09min19s)

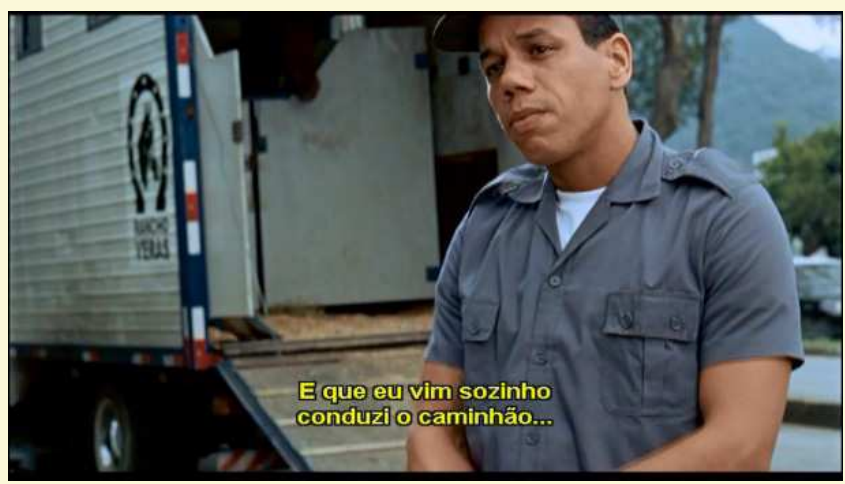

Figura 12 (31min8s)

Se, por um lado, a ausência da LSE compromete a interpretação e dificulta o entendimento dos surdos e ensurdecidos, o mesmo quase não ocorre com a $\mathrm{AD}$, que, de modo geral, está de acordo com as propostas do Guia. Observa-se que o audiodescritor optou por descrever mais as ações e que os momentos de silêncio não são todos preenchidos por descrição, evitando cansar o espectador.

Outros exemplos de situações que favorecem a compreensão do enredo são a antecipação de informação importante e a sobreposição da descrição ao diálogo não relevante. Aos $11 \mathrm{~min} 33 \mathrm{~s}$, o audiodescritor se refere a um rapaz que cruza o caminho de Maycon 
como "traficante". Contudo, nesse momento, não há como saber isso, portanto, trata-se da antecipação de uma informação, indispensável para o entendimento do enredo, porque depois dessa cena Maycon começa a repassar droga para os colegas de faculdade. Conforme orienta o Guia, é possível adiantar a unidade descritiva ou até mesmo atrasá-la, "desde que não antecipe fatos ou faça versões do que está previsto" (2016, p. 20), excepcionalmente quando a informação for importante.

Por outro lado, há algumas ocorrências que representam um problema na $\mathrm{AD}$. No primeiro curta-metragem, o audiodescritor se refere a Eduardo pelo nome errado (Fernando) e não descreve o momento em que Maycon entrega drogas para Eduardo, cabendo ao espectador deduzir isso pelo diálogo.

No quarto curta-metragem, na cena em que Flávio e seus amigos sobem na laje para soltar pipa com Pardal, um dos rapazes está empinando pipa quando o grupo rival corta a linha da sua pipa (1h02min15s). A AD descreve que "num plano mais baixo, há um outro grupo de garotos em outra laje também soltando pipas". Na sequência, descreve que "os garotos da laje mais baixa cortam a pipa do outro grupo". Essa descrição pode causar confusão, pois que outro grupo seria esse? Talvez substituir "outro grupo" por "grupo do Pardal" esclarecesse que se trata do grupo de Flávio e seus amigos.

Outro problema presente na $\mathrm{AD}$ desse curta-metragem é a pausa na construção de uma frase, que ocorre quando Flávio, Pardal e os outros rapazes que estavam soltando pipa e correm atrás da pipa avoada (1h05min20s). Na AD, ouve-se: "As imagens se alteram... entre os garotos... e a pipa voando à deriva no céu".

O último curta-metragem é o que apresenta mais desafios ao audiodescritor, pois há muitos personagens e diálogos. Logo no começo, quando Maria chega em casa com seus filhos e Cimar começa a conversar com ela, temos "vizinhos conversam entre si" e um breve diálogo entre eles (1h14min12s). Em seguida, Maria e seus filhos entram em casa e Cimar conversa com outro vizinho (1h14min 22s). Nesse momento não fica claro que Maria saiu de 
cena e que outro vizinho entrou em cena, o que poderia ser resolvido com a inserção de outra AD, "Maria e seus filhos entram em casa". A falta de descrição das mudanças de cena é recorrente ao longo do filme, o que pode resultar em incompreensão das sequências, principalmente no último episódio. Para lidar com essa situação, sugere-se que a AD seja concisa e que se sobreponha ao diálogo, quando esse não for relevante para o enredo.

Outro fato que chamou a atenção na $\mathrm{AD}$ do filme e que não poderia deixar de ser comentado diz respeito ao terceiro curta-metragem, Concerto para violino, considerado o mais estereotipado dos cinco por retratar tráfico de drogas e violência. Diferentemente dos outros curtas, em que a descrição prioriza ações, nesse episódio, o audiodescritor apresenta Jota como "rapaz branco e loiro" e Marcinha e sua família como "uma moça negra" e "uma senhora e uma garotinha negras”, contrariando a recomendação do Guia (já que não é relevante para a trama e reforça estereótipos).

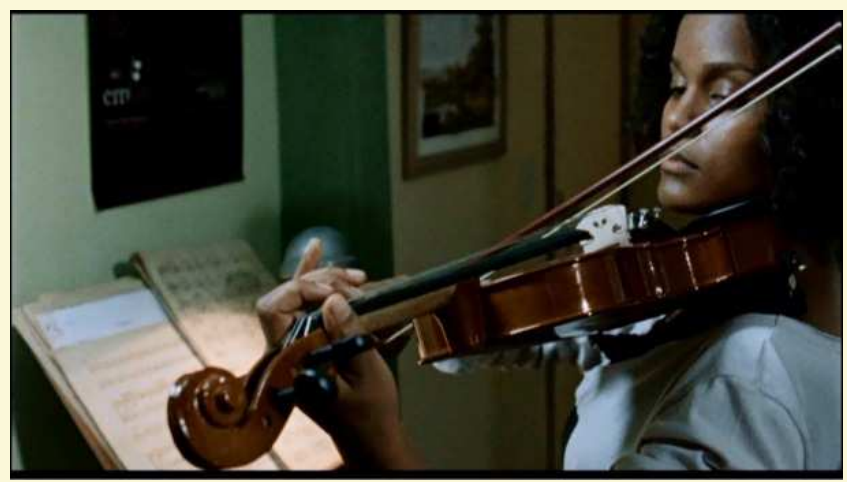

Figura 13: "uma moça negra" [42min30s]

\section{Considerações finais}

A partir da análise e com base na fundamentação teórica apresentada, é possível concluir que a legenda e a AD são determinan- 
tes para a construção do significado, por isso deveriam ser pensadas em conjunto com a equipe criativa do filme, como propõe Chaume (2004) e Romero-Fresco (2013). Além disso, o presente estudo possibilitou destacar as prioridades das modalidades de TAV aqui analisadas, confirmando que a legenda para ouvintes se concentra na informação sonora verbal, ao passo que a LSE precisa oferecer também a informação sonora não-verbal, especificando os efeitos sonoros e a trilha sonora, e deve identificar o falante sempre que houver troca de turno, em especial na presença de dois ou mais falantes em cena. Por outro lado, a AD deve marcar as mudanças de cena, para que o espectador acompanhe a sequência narrativa, e priorizar as informações visuais e a descrição das ações e dos personagens, o que pode ser verificado nos curtas, com exceção da figura 13, em que se descrevem características étnico-raciais de alguns personagens, e não de outros, inevitavelmente influenciando a maneira como o público que depende desse recurso receberá o filme.

Em todos os casos, o critério da relevância é fundamental, uma vez que o tradutor/audiodescritor precisa fazer escolhas ou por haver um limite de caracteres para a inserção de legenda ou por haver um limite de tempo entre os diálogos para a inserção da AD. Por essa razão, conclui-se que seria de extrema relevância um trabalho conjunto entre a equipe tradutória e a equipe criativa do filme, para a definição do que é importante na trama, princípio que norteia processo tradutório de qualquer produto audiovisual.

Embora haja um aumento significativo em pesquisas sobre TAV nos últimos anos, e algumas políticas de incentivo a uma maior acessibilidade, ainda há muito o que desenvolver na área e muito o que se investir, tanto em qualidade quanto em quantidade de produções que apresentem LSE e AD. É preciso, também, maior espaço, nos cursos de graduação de tradutores, para a formação de audiodescritores, com disciplinas específicas para AD e com reflexões éticas e cidadãs sobre o que realmente significa acessibilidade em TAV. 


\section{Referências}

ARAUJO, V. L. S. “Closed subtitling in Brazil”. In: ORERO, P. (ed). Topics in audiovisual translation. 1. ed. Amsterdã: John Benjamins, 2004, v. 1, p. 199212.

. “A legendagem para surdos no Brasil”. In: LIMA, P. L. C: ARAÚJO, A. D. (org.). Questões de Linguística Aplicada: miscelânea. Fortaleza: EdUECE, 2005, p. 163-188.

. "Subtitling for the deaf and hard-of-hearing in Brazil". In: DIAZCINTAS, J.; REMAEL, A.; ORERO, P. (ed.). Media for All: Subtitling for the Deaf, Audio Description and Sign Language.1. ed, Kenilworth, Nova Jersey, EUA: Rodopi, 2007, v. 30, p. 99-107.

. Por um modelo de legendagem para surdos no Brasil. Tradução \& Comunicação: Revista Brasileira de Tradutores, n. 17, 2008, p. 59-76.

ARAÚJO, V. L. S.; ALVES, S. F. (Org.); MAUCH, C. (Org.) ; NEVES, S. B. (Org.) . Guia para Produções Audiovisuais Acessíveis. 1. ed. Brasília: Ministério da Cultura/Secretaria do Audiovisual, 2016.

BENECKE, B. Audio-description. Meta: journal des traducteurs, vol. 48, n. 1, 2004, p. 78-80.

CASADO, A. B. La audiodescripción: apuntes sobre el estado de la cuestión y las perspectivas de investigatión. TradTerm-USP, n. 13, 2007, p. 151-169.

CHAUME, F. "Translating non-verbal communication in dubbing". In: POYATOS, F. (ed.): Nonverbal Communication and Translation. Amsterdam, John Benjamins, 1997, p. 315-326.

CHAUME, F. Film studies and translation studies: two disciplines at stake in audiovisual translation. Meta: journal des traducteurs, vol. 49, n. 1, 2004, p. $12-24$. 
DÍAZ CINTAS, J. Audiovisual Translation Today. A question of accessibility for all. Translating Today, v. 4, p. 3-5, 2005.

. "Traducción audiovisual y accesibilidad, Subtitulación para sordos y audiodescripción para ciegos: nuevas modalidades de traducción audiovisual". In: HURTADO, C. J. (ed.) Traducción audiovisual y acessibilidad. Frankfurt: Peter Lang, 2007, p. 9-23.

. "La accesibilidad a los medios de comunicación audiovisual a través del subtitulado y de la audiodescripción”. In: GONZÁLEZ, L; HERNÚÑEZ, P. (ed.) El español, lengua de traducción para la cooperación y el diálogo. Instituto Cervantes, 2010, p. 157-180.

FRANCO, E. P. C.; ARAÚJO, V. L. S. "Reading Television - Checking Deaf People's Reactions to Closed Subtitling in Fortaleza, Brazil". In: GAMBIER, Y. (ed). The translator. Manchester, 2003, v. 9, n. 2, p. 249-267.

. Questões terminológico-conceituais no campo da tradução audiovisual (TAV). Tradução em Revista, n. 11, 2011/12.

GAMBIER, Y. Introduction: Screen Transadaptation: Perceptionand Reception. The Translator. Special issue on Screen Translation, v. 9, n. 2, p. 191-205, 2003.

JAKOBSON, R. "Aspectos linguísticos da tradução". In: . Linguística e Comunicação. Tradução de Izidoro Blikstein e José Paulo Paes. Editora Cultrix: São Paulo-SP, [1963]2010, 24ª edição, p. 79-91.

ROMERO-FRESCO, P. Accessible filmmaking: joining the dots between audiovisual translation, accessibility and filmmaking. The Journal of Specialised Translation, 2013, p. 201-223.

"Accessible Filmmaking: Translation and Accessibility from Production". In: PÉREZ-GONZÁLEZ, Luis (ed.) The Routledge Handbook of Audiovisual Translation Studies, London/New York: Routledge, (no prelo) 2017.

5x favela, agora por nós mesmos. Direção Cacau Amaral, Cadu Barcelos, Luciana Bezerra, Luciano Vidigal, Manaíra Carneiro, Rodrigo Felha e Wagner Novais. Produção Renata de Almeida Magalhães e Carlos Diegues. Rio de Janeiro: 
Companhia Produtora Luz Mágica, Co-produtores Globo Filmes; Produtores Associados: Videofilmes, Quanta, Teleimage. 2010. DVD, 99min.

Recebido em: 03 novembro de 2017 Aceito em: 02 fevereiro de 2018

Publicado em: maio de 2018 